\title{
Features of the Organization of Construction with the Use of Technologies of Information Modeling
}

\author{
Tatyana Kisel $^{1, *}$ \\ ${ }^{1}$ Moscow State University of Civil Engineering, Yaroslavskoe shosse, 26, Moscow, 129337, Russia
}

\begin{abstract}
Gradual universal transition to the technologies of building information modeling (BIM technology) became the reply to the need of taking into account huge volumes of information during designing, construction and maintenance of buildings and structures. The possibility of such transition is caused by the intensive development of information technologies and the emergence of the specialized software products aimed on the creation computer (i.e. information) model of a construction project, including all the information about it. The availability of the computer model of the construction project allows to organize the process of designing, construction and maintenance of the building in a new way. This article is devoted to the features of the implementation of BIM technologies in Russia. It is based on the results of the research on the experience of implementation of BIM in various countries, on the problems of implementation of technologies of information modeling in Russia, and also on the effect which the leading Russian organizations in the implementation of BIM field could obtain, namely, the substantial increase of efficiency of the organization of the construction process.
\end{abstract}

\section{Introduction}

Gradual universal transition to technologies of information modeling of buildings and constructions (BIM technology) became the reply to the need of taking into account significant volume of information during designing, construction and maintenance of buildings and structures, subsequent (sometimes repeated) adjustment of data during the implementation process of the project. The possibility of such transition is caused by the intensive development of the information technologies and the emergence of the specialized software products aimed on the creation computer (i.e. information) model of construction project, including all the information about it. The availability of such computer model of the construction project allows to use the automated design tools and handlings data, as well as to provide the access to the project data for all the interested persons in the single information environment.

\footnotetext{
* Corresponding author: doremi2@yandex.ru
} 
The emergence of BIM became the consequence of the development of information technologies, as well as the of the fact that the industry's demand for it appeared. Nowadays construction is a high-tech industry. The implementation of investment-and-construction projects requires simultaneous taking into account of the set of factors, management of various processes including manual and automated work, work of employees of various specialties with the use of machines and mechanisms. The complexity of production process determines not only the high cost of production, but also the high expense level of administrative nature. The use of technologies of information modeling allows to cut expenses of production and non-productive expenses considerably because of numerous benefits. That allows to speak about BIM as about the technology solution, and also as about the business solution, business ideology based on the concept of economical production. Separately it should be noted that the concept is supported now not only by private, but also by the state customers. That determines the support, which was got at the national level by implementation of BIM technologies in some countries.

There is a lot of determinations of BIM, which are to a greater or lesser extent reflecting its essence, however their general sense comes down to the fact that BIM (in English Building Information Modeling - information modeling of buildings and structures) is the process of creation and management of information at all the stages of lifecycle of the construction project. So, one of the most widespread treatments determines BIM as the process of collective creation and the use of information on the construction, creating the basis for all the decisions for the lifecycle of the project (from planning to designing, preparing working documentation, construction, maintenance and demolition) $[1,2]$.

The cornerstone of BIM is the process of creation and joint use of three-dimensional model of the construction project by all the participants of the investment-and-construction process, however the possibilities of this technology are much wider than the creation of a 3D model for visualization and development of the project documentation: it allows to carry out accumulating and complex handling of all architectural and design, technological, economic and other information on the project both during designing, and during construction and the subsequent maintenance in a common information space collection. All this information is also necessary for planning, organization, coordination and control of purchase of materials, implementation project and construction-and-installation works, logistics, transfer to maintenance stage. The availability of such information on the project allows to make reasoned management decisions quickly, and thus increases efficiency and quality of management that, certainly, increases overall effectiveness of organization activity too [3].

The special advantage of BIM technology is that, the construction project model, created with its help is not static. Data can be corrected and be added to a 3D model throughout all the life cycle of the building or structure, providing the simultaneous automated updating of all the interconnected parameters.

Besides, BIM allows all the participants of the investment-and-construction process (customer, designer, builder, contract organizations, suppliers and operating organization) to be involved in the process of creation of the subject, to coordinate their actions, to monitor changes that also increase the efficiency of the work on the project.

It should be separately mentioned that the technology of information modeling of structures allows to increase the quality of designing considerably, as well as transferring it to a new level in respect of disaggregation, visualization and decrease in quantity of mistakes and disagreements. In spite of the fact that designing cost in the total cost of the investment-and-construction project occupies the insignificant share, however the mistakes, made at that stage by the designer can lead to significant unplanned costs and idle times during construction stages. The most particular mistakes made at the design stage are the collisions between structures of the building and its engineering networks, caused by 
insufficiently effective interaction between designers of different sections of the project documentation become obvious within a 3D model and automatically are found by the software product, which is supporting BIM [4].

\section{Materials and Methods}

The research which results are presented in this article consisted of several blocks. Within each block the certain method of the research was used.

The analysis of the experience of implementation of information technologies in various countries became the first investigation stage of the research. In this case the method of the analysis of the documents submitted to the main open sources was used. Besides, the results of the social researches devoted to the efficiency of implementation of BIM were studied. The results of researches were analyzed, using the comparison method.

Studying of the features of introduction of BIM in Russia became the second block of the research. The method of the analysis of documents was used too.

The analysis of features of the organization of construction with the application of BIM in Russia became the third block of the research. For studying of these features the methods of sociological research were used (including poll).

\section{Results}

The benefits of technology of information modeling of buildings and structures lead to its universal implementation in the world project practice and construction processes management practice. Processes of implementation of BIM take place in Russia as well. However at the moment it is possible to note that lagging from the western countries where the practice of broad application of BIM is already observed and allows to draw conclusions about the achievement of great speed, volume and quality of construction in combination with the increase in economical efficiency. Owing to the lack of sufficient information about the experience of application of BIM in Russia the deficit of information on economic indicators on the projects using BIM technologies is also observed. Nevertheless, the availability of such information is important for the further accelerating implementation of the technology of information modeling of buildings and structures, and for the involvement the increasing number of representatives of the investment-andconstruction sphere.

Nowadays in many countries all over of the world (USA, Great Britain, France, countries of Northern Europe, Singapore, South Korea, China, etc.) technologies of information modeling in construction take root intensively. Such rates of the implementation of BIM in the named countries are explained, first of all, by the benefits from the use of this technology. These benefits are gained in various spheres at various stages of project implementation and at various levels (at the level of the separate enterprise, industry and state in general).

So, the results of application of BIM appear in the form of high-quality of the project documentation, storage of information in the single information resource, improvements of information exchange and interaction of various participants of investment-andconstruction projects, cost reduction at the construction stage, etc. All that leads to the increase in cost efficiency of the implementation of projects of construction of buildings and structures, including decrease in cost value. These benefits can be noticed both at the level of the separate construction organization in the form of increase in profit level and profitability, and at the national level for the cost reduction because of the projects which 
are under construction according to the state order and, respectively, economy and more effective use of means of the government budget.

Owing to the considerable benefits from the use of BIM at the national level in some countries conditions for the obligatory use of the specified technologies during designing and constructing facilities at the expense of means of the government budget have been established. Similar requirements were gradually introduced by the state customers in the USA since 2003, and some countries of Europe and Asia since 2007.

In 2011 the new strategy in construction oriented to the achievement of competitive advantages at the world scene was declared by Great Britain [5]. Within this strategy the single consecutive program of transition to technologies of information modeling is implemented is developed and methodically worked. Within the programme the transition to the obligatory use of these technologies for all the projects, financed from the budget, including new construction, reconstruction, capital repairs since April, 2016 was also prepared. Such decision made at the national level provided the accelerated rates of implementation of BIM technologies.

In 2012 in the USA more than $70 \%$ of the participants of the construction market declared the use of technologies of information modeling in their projects (data of the company McGraw Hill Construction) [6], in Great Britain in 2013 the share makes up 54\% (according to NBS, National BIM Report 2014) [7]. According to the Singapore state agency on construction (BCA, Building \& Construction Authority), since 2015 more than $80 \%$ of all construction projects are carried out with the use of BIM technologies only. All the project organizations and about $70 \%$ of civil engineering contractors of Singapore apply $\mathrm{BIM}$ on the projects to the moment that is caused by state policy in this area [8].

In January, 2014 some amendments to the European directive on the state procurements were made. It was recommended to all the European Union countries to apply the electronic forms of work including BIM in construction for the sake of increase in transparency and efficiency of the expenditure of budgetary funds. Now the working group for state customers of the countries entering the European Union is organized and financed by European Commission.

According to some foreign analysts estimates, the implementation of technology of information modeling is capable to provide considerable cost reduction on construction of facilities, financed by the means of the government budget - for $25 \%$, and also the subsequent maintenance expense reduction - more than $35 \%$.

The analysis of the international experience of the efficiency evaluation of the use of BIM technologies in construction proved that in the countries, leading in the sphere of implementation of technologies of information modeling quantitative and high-quality effects of implementation of BIM are observed. The results of researches demonstrate that the application of BIM promotes the profit increase and profitability indicators, to cost reduction, performance improvement, decrease in the total cost of the project.

Besides, some decrease in the amount of requests for information and change requests, and also alterations on the project is observed which also reduces the cost level.

In addition to the net economic benefits, the application of BIM leads to lots of highquality benefits influencing business competitiveness growth:

- increase in automation of processes;

- decrease in project risks;

- increase in safety at the project site;

- improvement of quality of the project;

- increase in efficiency of communications between project participants.

All that in general proves the plurality of effects of the application of BIM and their positive orientation $[9,10]$. 
The achievement of proper results of the implementation of BIM and wide circulation of the technology in the leading countries became possible, first of all, at the expense of the state support and availability of state policy with accurately particular purposes and developed measures for their achievement.

BIM is not just a set of new programme tools supporting a new implementation process of the investment-and-construction project, it is the complex innovative technology. Its application at the enterprises of the construction industry allows to raise indicators of cost efficiency, and also to gain some effects of not economic nature. The action of these factors in total allows the organizations to move to the absolutely new level of work which is characterized by automation of many routine processes; organization of new processes of information transfer without loss; the improvement of work and quality of managerial decisions on each particular project. The importance of such not economic factor of efficiency can be so great that each one should be considered separately and on the equal principles with economic indicators $[11,12]$.

Consideration of high-quality effect of the implementation of BIM technologies in Russia is especially important nowadays. During the initial stage of the use of BIM technologies for some organizations, positive dynamics of financial performance is not observed. Such situation is rather standard in some cases connected with large investment costs and the necessity of restructuring of business processes. However even in case of temporary "flash" of economic indicators, transition to BIM gives the considerable highquality changes, leading to the increase in competitiveness of the organization and creating the prospects of its sustainable development in strategic prospect.

Features of this stage of the implementation of BIM in Russia include not only the need of high investment costs, but also the absence of qualified personnel, as well as also the effect of resistance to changes and commitment to habitual methods of designing, planning and management of investment-and-construction projects [13]. At the moment there is no information on the quantity (or on the share) of the Russian enterprises of the investmentand-construction sphere, which use BIM technologies. The researches allowing to make such assessment were not conducted. Only the insignificant number of organizations openly declare that they systemically use these technologies thus it is possible to conclude that in general the number of the organizations working with the use of BIM in Russia is not so great yet.

Now the implementation of BIM technologies in the Russian Federation is at the initial stage still. However many participants of the project-and-construction industry and it already realize the need for the fastest development of BIM technologies is acknowledged at the national level [14]. So, in the end of 2014 the Ministry of Construction of Russia, accepted the Plan of step-by-step implementation of technologies of information modeling in the field of industrial-and-civil engineering $[15,16]$.

As it was specified in the "Methodology" section, for the acquisition of data on features of the organization of construction with the use of technologies of information modeling the poll method in the form of questioning of the organizations, which take their active position concerning implementation of BIM technologies of the investment-and-construction sphere was used. The poll was completed on the voluntary basis. The organizations of various profiles of activities took part in it, including:

- project organizations;

- the organizations performing functions of investor, technical customer;

- builders, contract organizations;

- developing companies;

- operating organizations;

- organizations performing several functions in the production chain of creation and operation of the construction subject. 
Because of the absence of any data on the total amount of parent population, it is impossible to consider the survey results to be representable, however they represent results of the work of those participants of the market, who actively use BIM and speak about the received results openly.

Let's characterize the main results of the use of BIM technologies revealed by results of the conducted research:

1. Improvement of quality of the project, decrease in number of "alterations on the project".

It is possible to call confidently the high quality of the project as one of the most important factors of not economic nature. It was noted by all the participants of the research. The quality is proved just in the opportunity to implement 3D-visualization, which means the participation in decision making on the project development for a more wide range of participants but, first of all, the project orderer obtains the valuable information at the earlier stage. Respondents also note the decrease in number of "alterations" of the project at the level of $20-80 \%$, i.e. the use of BIM technology allows to increase the quality of the project in certain cases by 10 times. It is necessary to point out this fact, especially as alterations on the project at various stages of its implementation lead to the idle times and economic losses.

2. Increase in efficiency of design.

One of the effects revealed in the course of the analysis of foreign experience of the assessment of the cost efficiency of BIM is increase in efficiency of designing, including decrease in its duration.

Within this research completed on the Russian enterprises, which often have less work experience with technologies of information modeling than at their foreign colleagues it was revealed that already at the moment about $30 \%$ of respondents note decrease in terms of designing in the range from 5 to $40 \%$.

Another $30 \%$ of respondents speak about the increase in terms of design by $10-30 \%$; the others have not revealed change of terms of development of the project documentation (Figure 1):

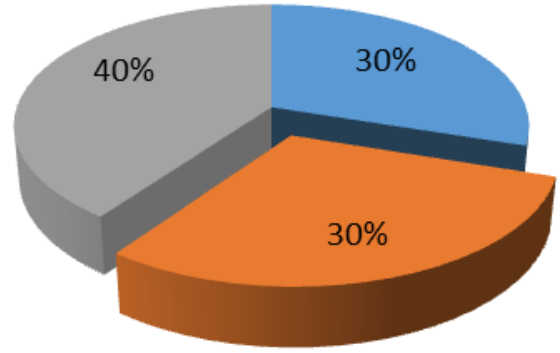

reduction of duration of designing in the range from 5 to $40 \%$

increase in duration of design by $10-30 \%$

changes in the duration of development of the project documentation were not revealed

Fig. 1. Change of the duration of development of the project documentation (results of the poll).

It is possible to explain the increase in the duration of designing at a part of respondents with the fact that technologies of information modeling require more detailed and highquality preparation and study of the project at earlier stages. That can bring to the project development process delay. The decrease in terms of designing is possible for the experienced users of BIM which are effectively applying the available practices (libraries of elements, nodes, setup of the project and so forth) and experience. The availability of 
practices allows their subsequent reuse and determines relative ease of modification of the project.

3. The observance of working schedules at the expense of high-quality planning and monitoring of the project progress.

Non-compliance with the planned dates of construction is one of the problems in the Russian construction industry. According to results of the conducted poll it is revealed that the high level of the study of the project developed by the means of technologies of information modeling, coordination of scheduling and network schedules with the elements of information modelling, visualization of the processes of construction of the facility allows to optimize the schedule and leads to the increase in accuracy of planning. Planning accuracy, and also the mechanisms allowing to perform high-quality monitoring of the work progress and to perform the timely adjusting impacts lead finally to the increase in accuracy of works schedules and allow to adhere to this schedule, without skirting construction deadlines.

4. Increase in safety at the construction site.

The important features of the construction industry are the capital intensity and duration of production, and also the specific working conditions connected with different risks. Safety and labor protections within the construction production - is the task of the high importance. Besides, different incidents cause idle times during production and lead to considerable losses. About $28 \%$ respondents note the increase in safety of the projects, which are realized with the use of BIM, they also note the reducing in the temporary losses, connected with various incidents. The others do not note considerable changes or do not keep the corresponding account at their enterprise.

5. Decrease in risks on the investment-and-construction project.

One more feature of the construction industry is the availability of the large amount of the versatile risks of projects implementation connected with their duration and influence of some external factors. In spite of the fact that certain participants of the investment-andconstruction sphere consider that risk management does not lie in the BIM plane, more than $40 \%$ of respondents note the decrease in risks as one of the effects of the not economic nature resulting in the decrease in financial losses (Figure 2). The decrease in risks in the range from 10 to $20 \%$ is noted.

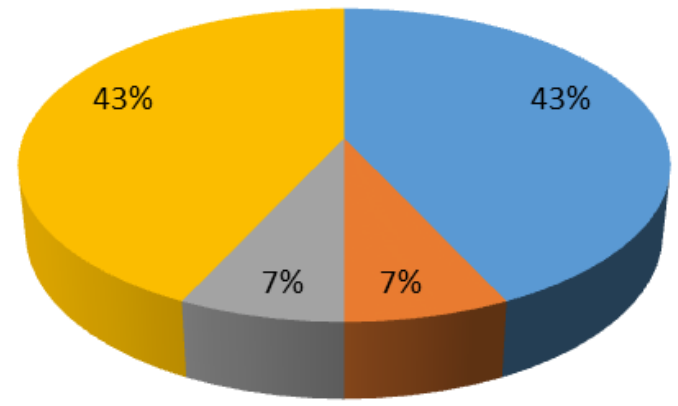

Reduction of project risks

The use of BIM does not influence on the risks

The reduction of the risks is not found

The change in risks is not traced

Fig. 2. Reduction of risks of the project with the use of BIM (poll results).

Reduction of risks in the range from 10 to $20 \%$ is noted. Similar reduction of risks is also noted by foreign researchers [17].

6. The increase in accuracy of planning and reduction of deviations from the project cost, calculated at the stage "P". 
Experts and experienced participants of the construction branch tell that the accuracy of calculation of amounts of works and development of estimates with the use of traditional technologies lead to deviations in project cost up to $10 \%$ (optimistical assessment). So, for the project worth 3 billion rubles the sum can make up 300 million rubles (Figure 3):

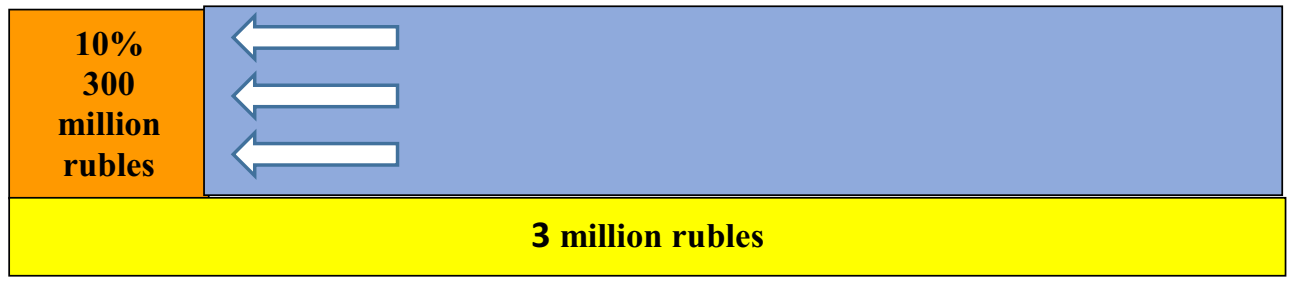

Fig. 3. "The mistake price" in the calculation of project cost.

In case of such deviations it is impossible to speak of efficiency of the use of resources. This question gains the special importance because one of the main investors in case of the implementation of investment-and-construction projects is the state undertaking liabilities on provision of housing for separate categories of citizens, construction of administrative buildings and creation of transport and social infrastructure. Realizing its liabilities through the projects of repeated application, government considers the increase in efficiency of construction, reducing its cost, adherence to deadlines, etc. as the priority task. I.e. the general increase in efficiency of the use of budgetary funds is the main task. According to this purpose, the potential reduction in cost of investment-and-construction projects to $10 \%$ shall lead to the fact that the majority of the investment-and-construction projects realized according to the state order will be performed with the mandatory requirement of the use of BIM technologies over time. Once again we will emphasize that for the cost reduction account of a construction projects of repeated application, including residential and administrative buildings, and also the subjects of the social infrastructure have the greatest upward potential of the budget efficiency.

7. Reduction of the duration of entering of adjustments into the project.

According to the poll results, 50\% of respondents noted reduction of terms of introduction of adjustments (the organizations note increase in speed of modification from $20 \%$ to $500 \%$ ). The increase in duration of works on adjustments during the research is not revealed.

8. Improvement of communications between participants of the investment-andconstruction project.

The use of technologies of information modeling improves the communications on the project between customers, designers and builders due to the access to the single information resource of urgent project information.

It allows to reduce temporary losses caused by communications, to accelerate the document flow thanks to the use a unified information system containing the most complete information about the project by all participants of the investment-and-construction project.

9. Visualization of the project.

Forming of three-dimensional model of the construction subject, considerably increases the visualization of the project (3D) for subcontractors, general contractor, supervisory authorities. It promotes forming of the single understanding of all the participants of investment-and-construction process about various parties of project implementation.

10. Improvement of control and monitoring of the construction process.

The opportunities of 3D and 4D visualization of the construction site ensures monitoring and control at the construction stage, including tracking of movement of personnel and equipment on an object, and also the performance of works in general according to the schedules approved. 
11. Increase in efficiency of the resources expenditure.

The high precision of the project, received with the help of 3D-modeling, allows to calculate the necessary amount of materials most precisely. It leads to the exact planning of purchasing amounts and cost reduction, including those of non-productive nature.

12. Parametrical coordination of documents.

All the documents developed with the use of technology of information modeling, which are in the uniform information environment, are connected among themselves (the project, schedules of works, budget documentation, etc.). The change of any parameter of the project automatically causes change of a complete set of documents and recalculation of indicators of the project. Such functionality provides considerable automation of processes and provides the simultaneous considering of changes, preventing emergence of mistakes and discrepancies.

13. The automated calculation of the project cost.

Basing on the information model of the subject and the estimate regulatory base, the specialized software products provide the automated calculation of works volume and calculation of the construction cost.

14. Reduction of number of requests for information and requirements of changes.

Requests for information and requirements of changes often cause stopping simple labor, cars and mechanisms. All that causes financial losses, as well as losses of time, resulting to failure to meet construction terms.

15. Reduction cost of seal, packaging, copying, sending, and receipt of documentation.

The need to unpack and send documentation to various participants of the investmentand-construction project in many cases can be replaced with the appeal to the unified information system comprising all the necessary information both about working documentation, and about the project course, schedule performance of works, its financial performance. The appeal to such system considerably reduces the costs of time and other resources connected with seal, copying, shipment of documents on the project.

16. Optimization of the schedule of production.

At a stage of planning optimization of the works schedule and the increase in efficiency of document flow are noted. That promotes more harmonious work of all the divisions in respect to distribution of labor power for the project, purchases of material resources, optimizations of cash flows, etc.

17. Accumulating of information necessary for the organization of high-quality operation.

At an operational stage high availability of information on the project for the maintenance in the digital format is noted, that also increases efficiency of operation and reduces costs of the operating organization.

Thus, different positive effects finally influencing on the increase in cost efficiency of the specific investment-and-construction project and results of activities of the enterprises in general are created at various stages of project implementation. And these effects are numerous.

As for such integrated effect of the use of BIM technologies as the complex business solution influencing the increase in competitiveness of the organization of the investmentand-construction sphere within the research it was revealed that assessment of such complex indicator for the separate organization is difficult. In fact, it is to become the analysis result of some indicators of organization activity, both before the implementation of technologies of information modeling, and later.

18. Growth of competitiveness during participation in tenders.

The use of innovative technologies including BIM is the competitive advantage of the organizations of the investment-and-construction sphere [18], however competitiveness can be estimated in different foreshortenings. The organizations often estimate their competitiveness as the opportunity to receive an order as the results of the tender. At the 
same time respondents were divided into 2 different groups, one of which is sure that the use of BIM technologies allows to win tenders and to be competitive in comparison with other representatives of the construction industry, others consider that there is the set of factors of competitiveness, at the same time the used technologies are not always the decisive factor.

The results of the analysis of all the factors of the organization of processes of construction and management of investment-and-construction projects which is carried out within this research allow to prove that the use of technologies of information modeling of construction subjects increases the enterprise competitiveness in the investment-andconstruction sphere, promotes the decrease in the cost level, reducing terms of construction, improvement of quality of the project and directly constructions, to decrease in risks and increase in safety, and also provides management with complete amount of information necessary for management decisions acceptance.

However there are some obstacles of wide circulation and universal implementation of BIM in Russia:

- high cost of initial investments connected with the procurement of equipment and software;

- deficit of the qualified personnel prepared for work with BIM technologies;

- infrastructure problems: shortcomings of the regulatory base and lack of single state standard of implementation of construction projects using technologies of information modeling on the blueprint stage, construction, maintenance.

\section{References}

1. V. Quirk, http://www.archdaily.com/302490/a-brief-history-of-bim (2012)

2. B. McNamara, GIS Center Symposium (2006)

3. C. Eastman, P. Teicholz, R. Sacks, K. Liston, BIM Handbook: A Guide to Building Information Modeling for Owners, Managers, Designers, Engineers and Contractors (2nd edition) (Wiley Publishing, Inc., 2011)

4. R. Burger, blog.capterra.com (2015)

5. Building Information Modelling. Industrial strategy: government and industry in partnership Projects (2012)

6. Smart Market Report McGraw Hill Construction (2012)

7. NBS National BIM Report (2014)

8. Singapore BIM Guide (Version 2) (2013)

9. V. Kupriyanovskiy, P. Tishchenko, S. Sinyagov., M. Raevskiy, S. Savelyev, V. Kononov, A. Sachik, ArcReview 2, 73 (2015)

10. McGraw Hill Construction Report on BIM and Large Projects (2015)

11. I. Kozlov, AMIT 1, 10 (2010)

12. D. Kulikovskiy, https://ais.by/article/bim-tehnologii-opyt-vnedreniya (2015)

13. V. Talapov, http://isicad.ru/ru/articles.php?article_num=14978 (2012)

14. Yu. Zhuk, http://rcmm.ru/tehnika-i-tehnologii/22401-pochemu-minstroy-predpochelbim-tehnologii.html (2015)

15. Plan of introduction of technologies of information modeling of buildings (BIM Building Information Modeling) in the field of civil engineering (2014)

16. A. Petuhova, http://dgng.pstu.ru/conf2016/papers/29/ (2016)

17. R. Burger, Construction management 1, 38 (2016) 
18. V. Grahov, S. Mokhnachev, A. Ishtryakov, Modern problems of science and education 1, 65 (2015)

19. A. Mottaeva, MATEC 73, 07020 (2016) 